\title{
Formulação e implementação da política de saúde no Estado do Rio de Janeiro
}

\author{
Silvia Gerschman \\ Débora Castanheira ${ }^{1}$
}

\begin{abstract}
RESUMO
O objetivo do artigo é analisar a formulação e a implementação da política de saúde no Estado do Rio de Janeiro (RJ), no espaço compreendido entre 2003 e 2012. A metodologia adotada procura compreender as dificuldades de capilarização do Sistema Único de Saúde (SUS) ao nível estadual, implicando nisso, a importância da gestão estadual na definição de políticas próprias para o estado, através de variados instrumentos de pesquisa social, contemplando metodologias de cunho qualitativo e quantitativo. Os principais resultados observados são que a implantação do SUS, por se dar em uma conjuntura adversa à intervenção do Estado, acabou por ser desvirtuada no que tange aos objetivos da descentralização e do aumento do controle social sobre a política de saúde. Além disso, a pactuação desta descentralização, inicialmente realizada diretamente junto aos municípios e à margem dos Estados federativos, contribuiu também para este resultado. Posteriomente, o estado do RJ consegue resgatar politicamente este controle através de uma participação mais ativa dos agentes estatais, mas com visível redução da importância da participação social devido à constatação da fraca atuação dos Conselhos na formulação das políticas de saúde estadual.
\end{abstract}

Palavras-chave: política de saúde; processo decisório; Constituição Federal; máquina política; Reforma Sanitária; participação social

\footnotetext{
ABSTRACT

The objective of this paper is to analyze the formulation and implementation of health policy in the state of Rio de Janeiro(RJ) in the space between 2003 and 2012. The methodology seeks to understand the difficulties of dissemination of the Unified Health

${ }^{1}$ Silvia Gerschman: Doutora em Ciências Sociais pela Universidade Estadual de Campinas (UNICAMP). Professora e pesquisadora titular da Escola Nacional de Saúde Pública (ENSP-FIOCRUZ). gerschman@ensp.fiocruz.br Débora Castanheira: Doutoranda em Ciência Política pelo Instituto de Estudos Sociais e Políticos da Universidade do Estado do Rio de Janeiro (IESP-UERJ). dcastanheira@iesp.uerj.br
} 
System (SUS) at the state level, implying that the importance of the State government in defining their own policies to the state through various instruments of social research methodologies contemplating nature qualitative and quantitative. The main results observed are that the process of implantation of the SUS, as happened in an adverse situation to state intervention, turned out to be distorted with respect to the objectives of decentralization and increase of social control over health policy. In addition, the pact of this decentralization initially performed directly with municipalities and outside the federal states, also contributed to this result. Afterwards, the state of RJ can redeem this political control through a more active participation of state agents, but with noticeable reduction of the importance of social participation due to the finding of lack of quality advice in the formulation of state health policies .

Keywords: health policy, decision-making process; Constitution; political machine; Healthcare Reform; social participation 


\section{Introdução}

O artigo que apresentamos a seguir é resultado de uma pesquisa que teve por objetivo analisar a política estadual de saúde no que se refere aos processos de formulação, implementação e participação, no Estado do Rio de Janeiro (RJ), no espaço compreendido entre 2003 e 2012. Na pesquisa pretende-se cobrir, de maneira genérica, por um lado, a produção governativa (Executivo e Legislativo) em relação à política estadual de saúde; e, por outro lado, produzir análises sobre as políticas públicas de saúde no Estado do RJ. O foco principal do projeto é a análise sobre a produção de políticas na Secretaria Estadual de Saúde (SES) e as proposições e deliberações do Conselho Estadual de Saúde (CES) referentes à produção da política estadual de saúde no RJ. O projeto propõe a elaboração de uma metodologia de acompanhamento e análise da implementação da política e a compreensão das dificuldades de capilarização do Sistema Único de Saúde (SUS) ao nível estadual, implicando nisso a importância da gestão estadual na definição de políticas próprias para o estado. $\mathrm{O}$ projeto foi realizado através de variados instrumentos de pesquisa social, contemplando metodologias de cunho qualitativo e quantitativo.

Para isto foram entrevistados os gestores da SES a respeito de várias questões, entre elas: as relações entre entes federativos; as relações público-privado; os processos decisórios na Secretaria; a política de Recursos Humanos; os programas e serviços de saúde; a rede assistencial e regionalização; a participação social; e o financiamento. Foram também entrevistados os conselheiros do CES a respeito da composição e papel do Conselho, do processo decisório e conflitos políticos, da relação entre Secretaria e Conselho, e das suas formas de representação.

A pesquisa abarcou um considerável leque de variáveis que compreendem o conteúdo do poder da gestão governamental. Ou, em síntese, a construção político organizacional e financeira da Secretaria Estadual de Saúde e do Conselho Estadual de Saúde.

Neste artigo trabalharemos apenas algumas das variáveis consideradas pela pesquisa. De uma parte, pela extensão da mesma que não é possível resumir em apenas um artigo e, de outra, a eleição de alguns parâmetros que acreditamos serem de maior interesse para o público da revista.

O artigo se divide nas seguintes seções, além desta Introdução e da Conclusão: na primeira seção apresentamos o contexto em que a política estadual foi concebida, a saber, a reforma sanitária e a implantação do SUS; na segunda seção descrevemos como a política 
estadual de saúde foi produzida, qual a relação entre os entes federativos, como se dão as relações entre o público e o privado e qual a percepção da participação social na Secretária Estadual de Saúde (SES); na terceira seção são explicitados os resultados das entrevistas acerca do perfil e participação social no Conselho Estadual de Saúde e os conflitos com a SES.

\section{A Reforma Sanitária e a implantação do SUS}

A Reforma Sanitária no Brasil, contexto no qual se concebeu a política de saúde no Estado do RJ, pode ser compreendida ao mesmo tempo como o projeto e a trajetória de constituição de um campo de saber, uma estratégia política e um processo de transformação institucional. Como construção teórica, a Reforma Sanitária faz parte de um processo de revisão da concepção marxista de Estado e da elaboração de uma leitura crítica do campo da saúde coletiva. Esta revisão coloca o Estado como um campo estratégico de lutas ${ }^{2}$ através das quais é possível reverter a "seletividade estrutural" do Estado, ${ }^{3}$ realizando rupturas reais na relação de poder, tencionando-a em direção às massas populares. Na saúde coletiva, esse processo se traduz na construção de um aparato teórico que privilegia o condicionamento da saúde pelas condições sociais.

Enquanto estratégia política, esta concepção foi carregada como luta pelo movimento sanitário que organiza estrategicamente diversos grupos em torno de propostas comuns. Importante salientar que a Reforma Sanitária brasileira foi proposta como mais que uma reforma setorial. Seu objetivo era a consolidação da democracia e da cidadania no país, por meio da asseguração do direito à saúde como um direito social básico.

Por fim, como processo de transformação institucional, temos a consolidação da saúde como um direito de cidadania na Constituição Federal de 1988. O reconhecimento da saúde como um bem público na $\mathrm{CF}$ abriu caminho para sua tradução em bases legais e normativas,

\footnotetext{
${ }^{2}$ Como afirma Poulantzas, o Estado não é um sujeito, mas uma relação social entre sujeitos. Ou seja, "como o 'capital', ele é [...] uma relação de forças ou, mais precisamente, a condensação material de tal relacionamento entre as classes e as frações de classe, da forma como ela é expressão no Estado em uma forma necessariamente específica" (Poulantzas, 1980:1). Assim, o Estado é por excelência o campo estratégico de lutas políticas que o constituem de forma orgânica, permitindo que se constitua como unidade de dominação.

${ }^{3} \mathrm{O}$ conceito de Offe de seletividade estrutural do Estado explica a maneira como demandas populares, mesmo quando alcançam o aparelho administrativo, são destituídas de seu conteúdo político nos meandros da burocracia estatal, preservando assim os limites do sistema de acumulação. Ver Offe (1984).
} 
inclusive nas Constituições Estaduais. A partir daí, contava-se com um marco legal que desenhava o organograma institucional do sistema de saúde brasileiro, com seus princípios e diretrizes e que culminou com a criação do Sistema Único de Saúde (SUS) pelas Leis 8142/90 e 8080/90. De fato, a reforma introduziu mudanças significativas no modo de operação do sistema, com um novo formato organizativo para os serviços de saúde sob a lógica da integralidade, descentralização municipalizante, regionalização, participação social e hierarquização.

Nesta seção do artigo, procuraremos entender o desenvolvimento institucional do SUS ao longo das últimas duas décadas e seu impacto sobre a lógica da Reforma Sanitária e fundadora do SUS. Nosso principal objetivo será entender como os avanços e retrocessos do processo de implantação do SUS configuram hoje o sistema de saúde, principalmente quanto às características essenciais de municipalização, regionalização e participação social. Nosso olhar recairá sobre a função dos estados enquanto entes federativos e, mais precisamente, sobre o Estado do Rio de Janeiro, considerado um caso crítico na implantação do sistema de saúde e que concentra em seu território diversas das tensões que são disseminadas em todo território nacional.

Esta não é uma preocupação menor e não se trata apenas de um balanço crítico das últimas décadas de SUS. Com efeito, há que se debruçar criticamente sobre o tema para que se possa avançar na própria implementação dos princípios e diretrizes do SUS, agora atentos à nova realidade política e econômica dos anos 2000. Refletir sobre os rumos de nossa democracia, da qual o SUS é uma parte importante, é um imperativo ético-político para todos aqueles interessados em fazer avançar a democracia social.

\subsection{Dilemas da implementação do SUS}

A existência do SUS é marcada por uma tensão estruturante entre instituinte e instituído. Como todo processo social, a construção de nosso modelo de saúde se deu em um ambiente complexo habitado pela diversidade das representações de interesses e em campos sociais de diferentes hierarquias, quais sejam, a ideológica, a política e a institucional. Com efeito, a construção do SUS foi operada a partir de sucessivas reduções da problemática do poder que, partindo da ampla disputa ideológica dos anos 1990 e de sua consequente transcrição nos atores políticos em disputa no campo da saúde pública, acabou por ser nucleada a partir de sua materialização institucional. Neste sentido, cada uma dessas 
dimensões hierárquicas representa amplitudes diferentes da disputa pelo poder, amplitudes essas pelas quais a reforma da saúde teve que passar em seu processo de implementação. Desta forma, uma vez que foi por meio de disputas e barganhas nestes três níveis hierárquicos que a reforma da saúde foi levada à frente, não é de surpreender que sua configuração não seja aquela na qual foi inicialmente proposta.

De fato, se a Constituição de 1988 buscou um modelo de saúde próximo daquele das social-democracias europeias, sua construção se deu em um contexto no qual a disputa ideológica favoreceu amplamente o projeto neoliberal, reorganizando as relações entre Estado e sociedade em bases distintas daquelas pressupostas pelos formuladores da Reforma.

Neste período acompanhamos, por exemplo, retrocessos importantes na construção da saúde como um valor público e direito coletivo. Na verdade, existe tal alteração na concepção de saúde que ela acaba por ser considerada como um bem de consumo posto no mercado. Como consequência desta transformação, ao contrário da proposta constitucional de substituição do modelo até então vigente no Brasil (corporativo, fragmentado por setores ocupacionais e de acesso limitado), por um sistema de atendimento universal e democrático, acontece o ingresso de um novo modelo baseado na individualização do risco: para aqueles que podem pagar por seus riscos sociais, seguros privados, para os que não podem, restam os programas de proteção focalizados. Fica reduzida em proporção a ideia central à qual o SUS está vinculado: todas as pessoas têm direito à saúde porque este direito está ligado à condição de cidadania. O sistema de saúde perde sua característica transformadora e democratizante, passando a integrar o mercado de troca de bens de consumo.

A conjuntura adversa aos projetos de corte universalista dos anos 1990 também contribuiu para a fragmentação das bases de apoio político da Reforma Sanitária. Sobre os profissionais de saúde - um dos principais grupos de suporte à Reforma, por exemplo -, Paim aponta que, diante da instabilidade econômica e consequente degradação das suas condições de trabalho e de remuneração, o longo trabalho de persuasão das categorias no sentido de reverter políticas individualistas de atendimento foi fragilizado. Além disso, "os preceitos neoliberais da política de RH [recursos humanos] na década de noventa se realizavam em detrimento da Reforma Sanitária, afastando os trabalhadores de sua sustentação" (Paim, 2008). 
Assim, como luta política, o processo de implementação do SUS marca a emergência de novos atores na cena política que, com o tempo, passam a ter predomínio sobre o movimento sanitário. Em outras palavras,

o êxito da reforma como fruto das lutas deste ator político, movimento sanitário, vai gerar, contraditoriamente, a superação deste caráter de movimento vindo da sociedade civil como crítica ao Estado, em direção a atores políticos que são parte da institucionalidade estatal, tais como os secretários municipais e estaduais de saúde, promotores públicos, a burocracia reformadora. (Fleury, 2009:750)

Quando o processo de reforma foi colocado em marcha, se impôs a necessidade de contemplar seus controversos componentes técnico-administrativos e técnico-operacionais, além de, sobretudo, lidar com a crise fiscal do Estado e com um conjunto de dispositivos jurídicos e administrativos que compõem a ossatura institucional deste estado e determinam as opções possíveis de implementação de políticas públicas. Na verdade, a variável institucional se mostra bastante importante para a transformação dos agentes políticos que capitanearam a institucionalização da Reforma Sanitária. Uma vez que cada passo de uma trajetória política iniciada em determinado ambiente institucional aumenta a atratividade relativa deste caminho para a próxima rodada de negociações - gerando um poderoso ciclo de autorreforço em que os custos de transação para outras alternativas aumentam consideravelmente com o tempo e tornam uma mudança radical ou reversão de curso cada vez menos prováveis, se bem que não impossíveis - é de se esperar que no momento em que a Reforma passa a encarar os problemas de organização administrativa ela fique altamente dependente do modelo normativo e hierárquico de nossa estrutura estatal. Tudo isso contribui para afastar a implementação da Reforma do controle do movimento sanitário, um ator que tem como base social a "coalizão de forças, cuja unidade é constituída em torno do desejo, da utopia” (Fleury, 1988:25) e sua concentração em atores provenientes do próprio Estado, que acabam por enfatizar os aspectos racionalizantes da Reforma Sanitária, minando, desta forma, sua base política, imprescindível para que esse processo transcenda os limites administrativos.

Já no que concerne ao nível hierárquico de organização institucional do Sistema Único de Saúde, o processo de construção é marcado por tensões que, apesar de fortemente influenciadas por lutas ideológicas e políticas, têm consequências próprias. A trajetória do processo de institucionalização do SUS - que tem como principal foco a implementação das diretrizes básicas de hierarquização, municipalização, regionalização e participação social - 
vai depender de modo significativo das escolhas feitas sobre a cronologia de implementação das diretrizes e dos problemas daí decorrentes. Vale dizer, os dilemas institucionais enfrentados atualmente pelo SUS são em parte decorrentes das alternativas deixadas em aberto pela escolhas feitas em seus momentos formativos iniciais.

O ponto aqui é que o aspecto institucional, agravado por problemas decorrentes da instabilidade do financiamento setorial, das formas de articulação entre o público e o privado, do clientelismo político e, de certa forma, da resistência do antigo modelo de atenção à saúde baseado na doença e nas ações curativas, acaba por ter um importante impacto na configuração atual do SUS e é fonte de alguns de seus principais problemas estruturais.

\subsection{Diretrizes do SUS e cronologia de implementação}

O SUS, enquanto instituição integrada por um conjunto de ações e serviços públicos de saúde, é uma organização em rede de forma regionalizada, descentralizada e hierarquizada. A diretriz da regionalização aponta para uma organização do sistema voltada para a noção de território, ela representa a articulação entre níveis de gestão para implementação de políticas, ações e serviços de saúde eficazmente baseados em perfis e indicadores regionais que sirvam de sustentação para a ordenação racional dos diversos tipos de atendimento em um determinado território. Já a diretriz de descentralização busca adequar o SUS à diversidade regional transferindo competências de gestão para os municípios, com a consequente transferência de recursos financeiros pela União, além de cooperação técnica. Tanto a regionalização quanto a descentralização só podem funcionar em um sistema hierarquizado, ou seja, segmentado em níveis de complexidade. No entanto, um sistema realmente eficiente e com definição clara de segmentações hierárquicas também depende largamente do aprofundamento do processo de definição de competências que é parte dos processos de regionalização e descentralização. Neste sentido, a hierarquização é um processo que ocorre em concomitância com aqueles de regionalização e municipalização.

Por outro lado, descentralização municipalizante e regionalização correspondem a momentos definidos na cronologia de implementação do SUS. A descentralização políticoadministrativa foi concebida compreendendo a "ênfase na descentralização dos serviços para os municípios", associada à "regionalização e hierarquização da rede de serviços de saúde" (art. $7^{\circ}$, Lei 8.080/90). Contudo, seguindo o movimento que marcou a descentralização das 
políticas sociais no Brasil na década de 1990, a opção política do primeiro decênio de implantação do SUS foi priorizar a municipalização da saúde.

Com efeito, a agenda de reformas do governo Fernando Henrique Cardoso visou rever o paradigma de centralização das políticas sociais brasileiras, partindo de um diagnóstico que atribuía à centralização federal a ineficiência e a corrupção das instituições civis precedentes e associava à descentralização formas mais ágeis, democráticas e eficientes de gestão (Arretche, 2002:453). Assim, a descentralização do sistema de saúde fez parte de um projeto político maior que envolvia reformas descentralizadoras nas áreas de habitação, saneamento e educação.

A primeira década do SUS foi marcada, portanto, por um processo intenso de reestruturação do arcabouço nacional de serviços de saúde, cuja principal consequência foi a transferência de recursos e atividades até então desempenhadas pelo governo federal para os municípios, orientada pelos instrumentos normativos emanados do Ministério da Saúde: as Normas Operacionais Básicas (NOBs). As NOBs 91, 92, 93 e 96 - que introduziram, respectivamente, o princípio da adesão ao SUS; a sistemática de repasse de recursos; as modalidades de habilitação distintas; e novas regras de transferência federais - foram os veículos de incentivo que possibilitaram o grande sucesso da municipalização que, já em 2000, contava com cerca de $99 \%$ dos municípios brasileiros habilitados.

A ênfase na dimensão municipalista da descentralização trouxe, sem dúvidas, avanços para o SUS, principalmente relacionados às vantagens de colocar a responsabilidade pela implementação de políticas públicas em níveis de governo mais próximos à fiscalização da população e de aumentar a oferta local de serviços públicos. Entretanto, a municipalização da saúde teve também impactos não previstos - mas nem por isso menos importantes - sobre a dinâmica das decisões políticas no SUS.

Com efeito, a implantação da municipalização com base numa prática de relação direta entre as esferas federal e municipal, adotada desde o início do processo, teve duas consequências importantes que definiram a trajetória de implementação do SUS. Em primeiro lugar, a primazia das relações entre União e municípios acabou por fragilizar as relações estabelecidas entre estados e municípios. Os estados perderam a gestão dos serviços e não ganharam poder decisório sobre a política de saúde, o que colocou a questão de qual seria sua função no SUS. 
Podemos ilustrar como a ênfase no processo de municipalização afetou o papel dos estados através de uma breve análise do processo de obtenção da gestão plena do sistema entre estados e municípios. A condição de Gestão Plena do Sistema (estadual ou municipal) de Saúde concede ao gestor uma maior autonomia para a condução do sistema de saúde e, de modo particular, altera a forma de participação do Ministério da Saúde no financiamento do SUS e na possibilidade do ente federativo de alterar normas sobre contratação e pagamento dentro de sua unidade territorial. Nesse caso, os recursos relativos à assistência de média e alta complexidade sob gestão da SES são automaticamente transferidos do Fundo Nacional para o Fundo Estadual de Saúde. Já aqueles referentes à atenção básica e aqueles relativos à assistência de média e alta complexidade sob gestão do Município em Gestão Plena do Sistema são transferidos do Fundo Nacional para os Fundos Municipais de Saúde.

A Gestão Plena do Sistema, tanto para estados quanto para municípios, foi tratada pela NOB/96. De acordo com dados do Ministério da Saúde, enquanto em 1998 83,5\% dos municípios (4.597) estavam habilitados na condição de Gestão Plena da Atenção Básica e 8,2\% (452) na condição de Gestão Plena do Sistema Municipal, nenhum estado havia conseguido finalizar seu processo de habilitação. Quando, em 2000, encontramos quatro estados habilitados em Gestão Plena do Sistema Estadual (Alagoas, Distrito Federal, Paraná e Santa Catarina) e quatro em Gestão Avançada do Sistema (Bahia, São Paulo, Minas Gerais e Rio Grande do Sul), já 99\% dos municípios estavam habilitados para Gestão Plena da Atenção Básica e 9,5\% em Gestão Plena do Sistema (Viana, 2002).

Assim, em razão do apoio do governo federal à municipalização, os municípios alcançaram antes dos estados a autonomia de gastos e normatização. Os estados, por outro lado, não tiveram incentivos financeiros para assumir essas novas posições de gestores plenos. Esta faceta do processo de descentralização limitará as opções que serão tomadas para o aprofundamento deste processo no SUS.

Em segundo lugar, como consequência da implantação da municipalização com base numa prática de relação direta entre as esferas federal e municipal, temos que a normatização do processo de municipalização, com um "emaranhado de normas operacionais e mecanismos de repasse de recursos financeiros" (Fleury, 2009:750), acabou por assegurar à burocracia central do Ministério da Saúde a preservação de poder, mesmo que isto tenha implicado o arrefecimento da participação política de movimentos sociais no SUS. 
Desta forma, a concentração política do processo de descentralização na esfera federal foi crucial para o alcance da municipalização, mas criou obstáculos para a conformação de mecanismos de coordenação federativa com incidência sobre relações intermunicipais, função que deveria ter sido desempenhada pelos governos estaduais. Esses fatores foram determinantes para a inflexão da condução política do SUS na década seguinte, no sentido da regionalização (Dourado, 2011). Neste sentido, estes dois aspectos - a falta de funções definidas para estados no SUS depois da primeira fase do processo de descentralização e a concentração de poder decisório nas mãos de membros do Poder Executivo - vão influenciar como serão encarados os problemas do SUS.

Na primeira década dos anos 2000 encaramos o reposicionamento da regionalização na agenda nacional. Depois de efetivada a descentralização via municipalização, tornou-se evidente que este processo apresenta desvantagens inequívocas. Uma delas acontece em situação de forte constrangimento dos recursos públicos. Em situações como esta, estabelecese uma competição entre os entes federados, em que cada qual pretende repassar os seus custos aos outros. Na área social esse mecanismo foi identificado como uma tentativa de cada nível de governo transferir a outro os custos políticos e financeiros das políticas sociais e reservar, para si, os benefícios delas decorrentes (Arretche, 1996). Outra se refere à tendência à fragmentação do serviço que, na verdade, exige escala para operar. Na verdade, foi a extrema fragmentação do sistema de saúde após as primeiras décadas de municipalização que tornou evidente que a estrutura municipalizada não era capaz de oferecer condições para a realização dos objetivos de universalidade do SUS. Identificou-se a necessidade de racionalização do sistema para equacionar a fragmentação da provisão de serviços e as disparidades de escala e capacidade produtiva existente entre os municípios (Dourado, 2011:207). O reconhecimento dessa situação levou ao caminho da regionalização com a Norma Operacional de Assistência à Saúde (NOAS).

$\mathrm{Na}$ verdade, já com a NOB 01/96 houve tentativa de fortalecimento do papel do estado, por meio da ampliação do funcionamento das Comissões Intergestoras Bipartites (CIBs) e da instituição das Programações Pactuadas e Integradas de Assistência à Saúde (PPIs). Todavia, isso não foi suficiente para a organização de redes assistenciais com base nos preceitos da regionalização.

Por esta razão, a regulação presente na NOAS tende a destacar o papel da instância estadual no processo de regionalização da assistência à saúde, tanto nos aspectos relativos ao 
planejamento, programação e controle, como nos investimentos que se façam necessários. Aqui a regionalização é enfatizada como estratégia necessária para a organização da rede de assistência, dando melhor funcionalidade ao sistema e permitindo aproveitamento integral dos serviços pela população. Neste sentido, a NOAS pretendia, seguindo o modelo federalista, incutir níveis regionais (módulos assistenciais, regiões, macrorregiões) entre estados e municípios.

Contudo, ao tentar fazer isso operando sobre a organização político-administrativa instituída, na qual a gestão dos sistemas já estava descentralizada para municípios, a efetivação da orientação operativa prevista na NOAS enfrentou importantes obstáculos. A atribuição de competência ao estado para o planejamento regional sofreu severa resistência por parte dos municípios que, já tendo adquirido autonomia na gestão da saúde, identificaram uma perspectiva de recentralização. Mais do que isso, a concentração política e financeira na esfera federal - que tanto serviu para que a indução operada pelo Ministério da Saúde através das NOBs tivesse sucesso na municipalização - criou uma série de constrangimentos para que a regionalização fosse implantada como diretriz organizativa do sistema.

Neste contexto de relegação do papel da esfera estadual nos primeiros anos do SUS e de pouca prática de mecanismos de coordenação federativa não é de se espantar que as propostas da NOAS não tenham sido bem sucedidas. Enfrentando estes problemas, ganhou força a ideia, desenvolvida no Ministério da Saúde e na CIT, de reforçar os mecanismos institucionais de negociação e pactuação entre os gestores para que as medidas adotadas partissem de compromissos efetuados entre as esferas de gestão. Com este objetivo foi aprovado o Pacto pela Saúde, em 2006, que afirma a condição da regionalização como elemento basilar do sistema e assume essa diretriz como "o eixo estruturante do Pacto de Gestão", devendo orientar o processo de descentralização e as relações intergovernamentais. O Plano organiza "regiões de saúde", a serem delimitadas a partir do entendimento entre gestores estaduais e municipais. Para operacionalizar o planejamento e gestão nessas regiões de saúde, foram criados os Colegiados de Gestão Regional (CGRs), instâncias deliberativas semelhantes às CIBs nas quais participariam os gestores municipais de cada uma das regiões.

Todo esse movimento pela regionalização acaba por fortalecer ainda mais os atores políticos institucionais, como os secretários de saúde estaduais e municipais, que passaram a contar com diversas instâncias de pactuação. As diversas tentativas de inclusão dos estados no processo decisório e na administração do SUS foram realizadas priorizando a participação de 
gestores e da própria burocracia estatal dos estados e municípios. A desigualdade na distribuição de recursos políticos e poder entre os atores é agravada e, com isso, tende a favorecer cada vez mais grupos de gestores e grupos corporativos, impedindo que os ideais da reforma se concretizem e garantam a centralidade do cidadão no processo decisório.

Todo este panorama deve estar sempre em vista agora que passamos à análise da política de saúde no Estado do Rio de Janeiro. Devemos compreender a atual situação política como fruto da combinação dos antecedentes históricos próprios deste estado, os quais passamos a tratar a seguir, e do desenvolvimento institucional do SUS a partir da Reforma Sanitária. Tal desenvolvimento passa pela tentativa de superação da municipalização e implantação de um modelo de regionalização, modelo este que se concentra na pactuação e negociação em conselhos gestores que, por privilegiar o poder decisório de gestores, acaba afastando o processo decisório do SUS do controle social.

\section{Produção de Políticas na Secretaria Estadual de Saúde}

Não é possível separar as políticas públicas/sociais do próprio Estado. Não há políticas sem Estado, as políticas públicas são cursos de ação aceitos e definidos pelas instituições estatais. A análise da política estadual de saúde será tratada a seguir não pelo conteúdo, direcionamentos e/ou efeitos, mas pelo processo produção/implementação das políticas e o papel que desempenham os gestores do mais alto escalão da burocracia da Secretaria Estadual de Saúde e os conselheiros do Conselho Estadual de Saúde, que exercem a participação e controle social, tal como o define a Constituição de 1988.

Ambos os atores são centrais na política de saúde estadual. Permanentemente estaremos nos referindo às duas gestões de governo do Estado no período 2003-2012. No caso trataremos da produção de políticas de saúde desde a perspectiva do formulador e não da sociedade. Mas, considerando que a Constituição deu um lugar à sociedade importante, na decisão da política, através dos Conselhos, cabe perguntar: qual a parte que a sociedade lhe toca através dos conselheiros na formulação da política de saúde?

O processo decisório se caracteriza por ser um dos momentos decisivos na definição da política, constituindo um importante ponto de partida para entender as relações de poder. As concepções sobre a distribuição do poder na sociedade atual, como também os métodos de 
análise que devem ser usados para seu estudo diferem bastante. Não apenas no marco conceitual das teorias (especialmente pluralistas e elitistas que trataram do assunto), mas ao próprio exercício do poder.

Embora exista consenso de que os conflitos sobre assuntos-chave fornecem evidências sobre a natureza da distribuição de poder, estas evidências precisam ser suplementadas por análises de não-tomada de decisão. Em alguns casos, a não-tomada de decisão assume a forma de decisão.

Bachach e Baratz em trabalho de 1962 afirmam que o exame do poder não poderia ficar restrito a decisões-chave ou a um comportamento efetivo. Estes autores formularam um complemento sobre o poder afirmando que "o poder também é exercido quando um ator A utiliza suas forças para criar ou reforçar valores sociais e políticos e práticas institucionais que venham a restringir o debate de questões de modo a se tornar politicamente inócuas para A" (Lukes, 1974). Esta definição dá origem aos conceitos de mobilização de opinião ou de conformação do processo político a questões seguras.

A maioria dos gestores $(89,7 \%)$ que definem políticas na SES entende que há mecanismos e procedimentos definidos para a tomada de decisão, mas esta ideia geral sobre o processo não se evidencia em relação a quais procedimentos/mecanismos utilizados. Estes mecanismos utilizados para a tomada de decisão não são consensuais para o conjunto dos secretários mas extremamente difusos. Os dois mecanismos mais mencionados são através de um colegiado de subsecretários $(53,8)$ e por meio de reuniões com o secretário de Saúde $(30,8)$; os restantes gestores entendem a questão de maneiras diversas. De fato, a forma em que acontece o processo decisório não envolve procedimentos recorrentes e previstos previamente à escolha de quem vai e quem não vai participar e também não envolve um conjunto permanente de subsecretários e assessores, sendo que parte destes entende que isto depende do tipo de decisão.

Quando se trata de processo decisório relativo a portarias, políticas ou programas do Executivo federal, também a forma de decidir sobre a matéria é através de reunião entre o secretário de Saúde, os assessores e subsecretários (43,6\%); para outro grupo de gestores do primeiro escalão é por meio de consulta com o governador $(35,9 \%)$. No caso, também os procedimentos utilizados dividem as opiniões dos subsecretários e assessores. Vários respondem que depende do tipo de decisão (20,5\%). A ideia que predomina entre estes 
gestores é de que não há nenhuma regularidade sobre os mecanismos utilizados nos processos decisórios existentes na SES.

Ainda que não tenham sido encontrados arquivos de reuniões nem da gestão atual nem da anterior, quando indagados os gestores sobre a modalidade de registro das reuniões, 38,5\% afirmam a existência de atas para todas as reuniões, sendo que o mesmo percentual informa que os registros são esparsos. De fato, se existirem registros, estes não puderam ser achados para nenhuma das duas gestões. Comparando as duas gestões, estas não evidenciam importantes diferenças.

Deixar registros de como se tomam as decisões e dos resultados das mesmas parece não ser uma preocupação do Executivo estadual da saúde. A não existência de registros se relaciona com a transparência da gestão, mas não apenas; se levarmos em consideração que em toda instituição existem diferenças entre as preferências políticas dos atores, o procedimento observado poderia se relacionar com o resguardo de conflitos políticoideológicos intrainstitucionais.

Os autores citados acima afirmam que o exame do poder se refere às decisões-chave que são resguardadas de interferências de poder e, neste sentido, cabe à gestão evitar que visões político-ideológicas ou de valores possam provocar rupturas ou dificuldades para o bom andamento da política. Assim, a transparência do processo decisório e das políticas efetivamente tomadas podem ocupar um segundo plano perante o exercício da governança do Executivo estadual de saúde. De fato a democratização das decisões governamentais é reconhecida pelos atores sempre que não afetem o "desempenho" do controle institucional.

A Constituição de 1988 reconsidera o papel de estados e municípios perante a União redefinindo o Pacto Federativo que passa a ter como eixo a descentralização das definições políticas, recursos financeiros e fundamentalmente serviços nas instâncias descentralizadas em estados e municípios (Gerschman, 2001). O Movimento Sanitário interpretava a descentralização como um instrumento político de singular importância para a redistribuição do poder e recursos concentrados na União.

Nesse sentido, a proximidade do Sistema Único de Saúde à sociedade retomava os princípios municipalistas tão em voga na época. Junto com a criação de novos municípios viria a transferência de recursos e de poder político institucional para os municípios e as sociedades locais. A VIII Conferência Nacional de Saúde - ícone da Reforma Sanitária - foi seguida pela IX Conferência Nacional, cuja orientação, em seu título - "Municipalizar é o 
Caminho", expressava a continuidade da proposta constitucional e o adensamento da democracia. Mas de uma parte, como se diz acima, faltou uma proposta do movimento para a conjuntura bastante desfavorável ao SUS no momento em que amplas restrições colocavam-se para a ampliação do investimento do setor público.

A política econômica da conjuntura dos anos 1990, com a globalização financeira à qual todos os países aderiram, exigia dos governos e, principalmente dos latino-americanos, o corte dos gastos governamentais, o pagamento da dívida externa, zero investimento em políticas sociais e em subsídios para o desenvolvimento industrial. No Brasil não foi diferente. Neste contexto das reformas neoliberais do Estado, a municipalização significava transladar o gasto para os municípios poupando à Federação de financiar a atenção pública à saúde.

A independência e/ou maioridade dos municípios exigia que estes entes federados reivindicassem que a municipalização dos serviços deveria ir acompanhada do financiamento dos mesmos. Os serviços de saúde podiam ser recepcionadas localmente sempre que fossem devidamente financiados pela Federação. Neste contexto, o pacto federativo, tal como definido constitucionalmente, foi por água abaixo. As relações de solidariedade e partilha entre União, Estados e Municípios se esvaziam deixando as relações interfederativas em um jogo de interesses em pugna entre serviços de saúde municipalizados e o Ministério de Saúde. Como visto, a negociação foi se inclinando à relação direta entre o MS e os municípios enquanto os estados careciam de definição de um papel na gestão do SUS, além de gerir a escassa rede estadual que possuíam de muito tempo atrás. Este modelo de relações interfederativas na saúde levou a uma considerável fragmentação do SUS. Enquanto a alternativa para o estado se limitava a aderir às portarias do Ministério da Saúde no que se refere aos estados e receber pagamentos por produção de atendimentos.

É na gestão da 2007-2012 que o Estado de Rio de Janeiro passa a ter um papel importante na saúde, na política e na economia. Esta importância se deve à aproximação do governador Sergio Cabral com a Presidência de Lula e posteriormente a de Dilma Rousseff. Consequentemente, no governo da saúde se reproduzem as relações políticas existentes entre os chefes de governo estadual e federal. Além da regionalização se tornar carro chefe do MS e o Estado consequentemente a implanta, o governo da saúde do Estado cria seu próprio carro chefe, uma política própria e separada do SUS, que foram as Unidades de Pronto 
Atendimento (UPAS), unidades de emergência e pronto atendimento muito bem quistas pela presidente da Nação.

A regionalização é parte da definição constitucional, mas não implementada até recentemente. Diversas portarias se referem a ela, mas a Norma Operacional de Assistência à Saúde de 2010 formula os lineamentos para sua operacionalização. Desde 2010 a Portaria de 2011 define as Redes de Atenção à Saúde tornando a regionalização como principal política para o SUS pela presidente.

Acreditamos que as relações federativas não enveredam pela construção de um Pacto Federativo que envolva os estados, municípios e União na Federação. Trata-se de acordos que se regem por "afinidades eletivas" político-partidárias e, por sua vez, os partidos respondem às suas hierarquias políticas e, principalmente, àquelas que exercem o poder.

Para compreender como se dá este tipo de relações observamos alguns dados comparativos entre as duas gestões da saúde, 2003-2007 e 2007-2012, no que se refere às relações federativas. A avaliação da relação entre o Estado, municípios e Federação no marco do SUS mostra um aumento expressivo de avaliações positivas na gestão 2007-2012. Enquanto na gestão 2003-2007 somente 38,5\% avaliavam a relação como cooperativa, este número cresce para 69,2\% na gestão 2007-2012. É importante notar também que 30,8\% dos entrevistados do período 2003-2007 consideraram a relação antagônica contra nenhuma avaliação antagônica dos gestores 2007-2012. Também vemos uma diminuição do numero de avaliações "pouco estabelecidas/definidas" (de 23,1\% para 15,4\%), também diminui o percentual de avaliações "não são claras/estabelecidas" (de 7,7\% para 3,8\%).

Já no que se refere à relação do estado com os municípios, não tem permanecido iguais ao longo do tempo. De uma parte pela própria história das sucessivas mudanças pelas quais passou a população do estado até a sua conformação nos dias de hoje. Os municípios pertenciam a um estado pobre que albergava uma capital rica, bela e sede de uma burocracia ilustrada que contrastava profundamente com a sociedade alhures da capital. Posteriormente, a existência de dois estados e, por último, a capital se tornar município sede da capital do governo estadual. Estas mudanças todas criaram uma distância entre os municípios e o município do Rio de Janeiro. Por sua vez o Estado do Rio de Janeiro precisou se adequar a governar não apenas seu município, mas o conjunto do Estado. De fato, os municípios tinham bastante pouca influência no governo estadual. Isto muda profundamente com a municipalização das políticas de saúde e com o achado de importantes jazidas de petróleo no 
estado. A partir daí os primos pobres se tornam ricos e os municípios com os repasses diretos para atenção à saúde se encontram com um recurso que não existia. As relações estadomunicípios que não estavam estabelecidas passam a ser parte da política estadual. Mas agora vem um novo problema a calar as relações político-partidárias entre estado e município do Rio de Janeiro. Quem fica com a máquina política e as decisões econômicas que o crescimento trouxe? Esta pendência marcou as relações do estado com os municípios e permaneceu até o governo de Sergio Cabral e a prefeitura de Eduardo Paes. De uma parte as estreitas relações do governador com a presidenta e, de outra, as estreitas relações do governador com o prefeito do Rio de Janeiro, podem ser vistas muito bem no termômetro das políticas de saúde através dos resultados da pesquisa.

Vemos uma divisão bem clara entre os dois períodos de tempo estudados. Enquanto 76,9\% dos entrevistados da gestão 2007-2012 responderam que a Secretaria mantém relações cooperativas com todos os municípios do estado, o percentual de respostas "todos" para o período 2003-2007 cai para 38,5\%, também neste período aparece com percentual significativo $(38,5 \%)$ a resposta "todos, menos o Rio de Janeiro".

Quando perguntados sobre com quais municípios a SES-RJ mantém (ou mantinha, no caso dos membros da gestão anterior) relações cooperativas, vemos que $64,1 \%$ dos entrevistados responderam que as relações são cooperativas com todos os municípios do estado, $12,8 \%$ responderam que as relações eram cooperativas com todos os municípios, exceto o município do Rio de Janeiro e 2,6\% responderam que as relações não eram cooperativas com os municípios que possuíam gestão plena.

No entanto, as diferenças importantes registradas nas relações cooperativas entre estado e Federação, na gestão da saúde nos períodos 2003-2007 e 2007-2011, não são observadas no que se refere ao tipo de relação do Estado com os municípios.

Os motivos apresentados para a classificação não variam muito de acordo com a gestão. Os entrevistados do período 2003-2007 tendiam a atribuir a classificação cooperativa a características da gestão como a "existência de apoio técnico aos municípios" (46,2\%). No entanto, os mecanismos de coordenação próprios do SUS também aparecem: "existência de um Plano Diretor de Regionalização (PDR) e de um Plano Diretor de Investimentos (PDI)" aparecem apenas em 15,4\% das entrevistas, e a "existência de um Plano de Saúde Estadual" em apenas $23,1 \%$. Outros motivos para a classificação que aparecem nas entrevistas são “Apoio financeiro" (em 15,4\% das entrevistas) e "Acordo político" (7,7\%). 
No período 2007-2012 a situação é muito semelhante, alterando-se apenas a menor importância dada aos mecanismos de coordenação do SUS. A explicação "apoio técnico" também aparece com frequência, 61,5\% das entrevistas, e também "apoio financeiro", 38,5\%. Outros motivos são a existência de um programa criado na gestão atual, o Plano de Auxílio aos Hospitais do Interior (PAHI), com 11,5\% de ocorrência, e o "Acordo político", com apenas $3,8 \%$. Vemos que entrevistados de ambas as gestões consideraram a existência de acordo político com os municípios do Estado irrelevante para explicar a relação cooperativa com estes.

Mas vale a pena observar que, se bem a relação estado-municípios não varia entre as duas gestões, isto muda quando se trata do Município do Rio de Janeiro. Interessante notar que $95,5 \%$ das entrevistas válidas responderam que existem mudanças nas relações estabelecidas entre a SES-RJ e a SMS-RJ. A maior mudança atribuída foi a "maior cooperação técnica e financeira" (com 73,7\%), seguida por "melhor comunicação" e "perda da gestão plena pelo Município do Rio de Janeiro", ambas com 10,5\%, e "Estado mais presente na proposição de políticas”, com 5,3\%.

Nada menos que $100 \%$ das entrevistas válidas apontaram que a cooperação da SES-RJ com a SMS-RJ beneficia a gestão estadual. Quando pedidos para quantificar este benefício, $69,6 \%$ dos entrevistados deram notas entre 8 e 10, 26,1\% deram notas entre 5 e 7 e 4,3\% deram notas entre 0 e 4 . No que tange aos benefícios reais desta cooperação, os entrevistados consideraram que ela era mais importante para o "planejamento e programação no uso de serviços" (79,5\% consideraram "muito importante" e 17,9\% “importante"), seguido da tomada de "decisões conjuntas entre estado e município" (79,5\% "muito importante", 15,4\% "importante" e 2,6\% "pouco importante"), em terceiro lugar ficou o "desenvolvimento de programas conjuntos" (71,8\% "muito importante", 15,4\% “importante", 7,7\% "pouco importante" e 5,1\% "indiferente"), a seguir temos a categoria "incentivando a integralidade da atenção" (64,1\% "muito importante", 23,1\% “importante", 5,1\% "pouco importante", 2,6\% "indiferente") e, por último, a categoria "promovendo a regionalização do sistema" (69,2\% "muito importante", 15,4\% “importante", 10,3\% "pouco importante" e 5,1\% “indiferente"). Outros benefícios citados foram: "alinhamento de planejamento estratégico entre os entes", "definição em relação ao financiamento", "ampliação dos espaços colegiados regionais", "planejamento e programação da vigilância sanitária, epidemiológica e ambiental” e "regulação de complexos". 
De uma parte, a cooperação entre estado e municípios é bastante irregular nas duas gestões, no entanto a coalizão política partidária entre o governo estadual e federal contribuiria bastante para implementar os programas no estado, o que permite analisar que a gestão das políticas nos municípios do estado não é fácil sem a colaboração/apoio do governo federal. A seguir podemos visualizar a leitura que os gestores do primeiro escalão fazem a respeito da importância da contribuição do governo federal:

A maior contribuição seria a "facilitação para a implantação de programas" que para $50 \%$ é muito importante; em segundo lugar veio a "coordenação de políticas e programas": 46,2\%; em terceiro lugar a "coordenação interfederativa no investimento na rede"; na quarta posição a "decisão conjunta de problemas da rede"; na quinta posição temos o "apoio do Ministério da Saúde para a gestão estadual"; por último a "formação e capacitação de recursos humanos": $30,8 \%$.

Ainda que a coalizão político-partidária seja vista como benéfica pelos gestores do primeiro escalão, em relação ao financiamento os gestores se dividem. A importância da coalizão parece ser mais política do que financeira. $\mathrm{O}$ apoio do governo federal a programas de saúde estaduais, como foi com as UPAS, sem dúvida tem contribuído com o governo estadual e com a SES. Uma parte importante dos gestores que acredita que a relação políticopartidária teve influência positiva sobre o financiamento da saúde expressa que a principal ajuda é na captação de recursos federais. Ao mesmo tempo, uma parte importante dos gestores acredita que o desenvolvimento das UPAS é relacionado à coalizão política partidária. O cenário que se observa é bastante interessante.

Os percentuais de gestores para "Sim" e "Não" foram os mesmos, 38,4\% (ou 50\% das entrevistas válidas); há um elevado percentual de gestores que não souberam ou não responderam, 23,2\%. Mas os gestores que responderam positivamente também se dividem. Dentre os que disseram "SIM", 70\% entendem que houve "facilitação na captação de recursos federais" e 30\% que "houve melhora, mas não sabem se foi em razão da coalizão".

Mas quando perguntados quais tipos de ações e projetos na SES-RJ tiveram melhor desenvolvimento pelo fato de haver uma coalizão com o nível federal, a maior incidência de respostas foi "Unidades de Pronto Atendimento (UPAS)", com 59\% de questionários apresentando esta opção, em seguida vieram "Programa de Saúde da Família (PSF)", com $41 \%$, "Programa de agentes comunitários de saúde", com 20,5\%, e "acompanhamento das 
condicionalidades do Bolsa Família", com 10,3\%. Importante notar que $13 \%$ dos entrevistados não consideraram existir nenhum programa com melhor desenvolvimento em razão da coalizão político-partidária. Os percentuais não somam 100\% porque, para cada uma das opções, foi solicitado marcar a resposta em uma escala de importância. Assim o percentual consignado se refere à atribuição "muito importante".

O programa que constitui o carro chefe da SES é, sem dúvida, as UPAS. Este programa se origina na esfera estadual e visa a criação de unidades pré hospitalares para atenção de urgências e emergências, trata-se de unidades de media complexidade. No total sumam 27 unidades no Estado e se distribuem no Município RJ, na baixada fluminense, em Niterói e em outros municípios do interior do Estado. A sua gestão não se integra ao SUS por não estarem referenciadas e contra referenciadas a hospitais de media e alta complexidade e também o sistema de organização e administração não ser público. Ou seja, as UPAs configuram uma unidade intermediaria entre as Unidades Básicas de Saúde e os hospitais de média e alta complexidade.

Por outro lado, a gestão está em mãos de organizações sociais e os recursos humanos são contratados diretamente pelas OSs sob a forma de terceirização. Aí também vemos que, de fato, a gestão não é pública e também não se homologa ao modelo empresarial privado. De modo geral estas OSs são subsidiadas pelo governo e, com efeito, se trata do conhecido "mix público privado" ou parcerias de gestão. Importante lembrar que não existiam UPAs na gestão 2003-2007.

Na gestão 2007-2012, os principais programas indicados como não originados na esfera federal foram as "Unidades de Pronto Atendimento (UPAs)" e "Programa de Auxílio aos Hospitais do Interior (PAHI)", ambos aparecendo em 42,3\% dos questionários desta gestão, seguidos de "Rio Imagem" (34,6\%), "co-financiamento da atenção básica" (23\%) e "hospitais de campanha" (7,6\%). Importante notar que 7,6\% dos entrevistados não lembravam de nenhum programa. Já na gestão 2003-2007, os programas indicados foram a "Farmácia Popular" (27,3\%) e "Projetos de qualificação profissional" (27,3\%).

As instâncias interfederativas do SUS tiveram uma importante avaliação pelos gestores, especialmente daquelas instâncias em que participam a SES, ou seja, a Comissão Intergestora Tripartite (CIT): formada por um representante do Ministério da Saúde, um do Conselho Nacional de Secretários Estaduais de Saúde (CNASS) e um do Conselho Nacional de Secretários Municipais de Saúde (COSEMS). A Comissão Intergestora Bipartite (CIB) é 
formada pelo secretário estadual e pelo COSEMS. E o Conselho Nacional de Saúde (CNS) é formado por $50 \%$ dos representantes de associações/instituições da sociedade, $25 \%$ dos gestores e $25 \%$ de representantes dos profissionais de saúde. Os percentuais chamam a atenção para o fato de que as instâncias federativas com avaliação mais baixa foram as que menor ingerência nas decisões cabíveis ao Estado.

Quando chamados a atribuir uma nota de 0 a 10 que expressasse o desempenho da SES-RJ nas instâncias colegiadas do SUS, vemos que a instância com melhor avaliação foi a CIT (77,3\% das notas se concentraram em 9 e 10), seguida de perto pelo COSEMS-RJ (75\% entre 9 e 10). A terceira instância com melhor avaliação foi a CIB-RJ (71,9\% entre 9 e 10), seguida pelo CONASS (69,6\% entre 9 e 10), em quarto lugar e pelo CNS (45,5\% entre 9 e 10).

Em relação às mais importantes atribuições desenvolvidas pela SES-RJ nas instâncias colegiadas do SUS, cabe notar que, apesar da enorme importância atribuída à CIT, a maior incidência de respostas foi "não sabe/não respondeu" (71,8\%), sendo este índice igualmente alto nos dois períodos (61,5\% em 2003-2007 e 76,9\% em 2007-2012). A segunda resposta foi “representação do estado no nível federal", com 28,2\% (38,5\% em 2003-2007 e 28,2\% em 2007-2012). Esta não era, de modo algum, uma resposta esperada e evidencia a falta de reflexão sobre o papel do estado na formulação da política de saúde. O fato, a grande incidência de não respostas, se repete com o COSEMS-RJ, ${ }^{4}$ com o CONASS e com o CNS.

Somente para a CIB-RJ encontramos uma resposta adequada sobre a função do estado. A função mais importante apontada foi a "pactuação/articulação/democratização" (com $53,8 \%)$, seguida de "suporte técnico para decisões" (5,1\%). Todavia, o número de não

\footnotetext{
${ }^{4}$ Para o COSEMS-RJ, vemos que novamente a maior incidência de respostas é "não sabe/não respondeu", com 53,8\% (46,2\% em 2003-2007 e 57,7\% em 2007-2012). Em segundo lugar temos a "definição de ações conjuntas", com 33,3\% (46,2\% em 2003-2007 e 26,9\% em 2007-2012), em terceiro lugar temos "representação dos municípios", com 10,3\% (7,7\% em 2003-2007 e 11,5\% em 2007-2012). No período 2007-2012 temos uma resposta isolada "não há atribuição específica, discute questões que serão levadas à CIB". No CONASS, vemos que novamente a maior incidência de respostas é "não sabe/não respondeu", 59\% (46,2\% em 2003-2007 e 65,4\% em 2007-2012). Em segundo lugar, vemos a resposta "representação dos problemas do estado", com 28,2\% (46,2\% em 2003-2007 e 19,2\% em 2007-2012), em terceiro lugar temos a opção "troca de experiências de gestão", 7,7\% (esta resposta aparece apenas no período 2007-2012 e representa $11,5 \%$ do total do período). Outras respostas representam 5,1\% do total. Para o CNS, mais uma vez a maior percentagem é de "não sabe/não respondeu", $69,2 \%$ do total (61,5\% em 2003-2007 e 73,1\% em 2007-2012). Em seguida, temos "definição de diretrizes para a saúde", $12,8 \%$ (23,1\% em 2003-2007 e 7,7\% em 2007-2012) e "controle social", também com $12,8 \%$ (7,7\% em 2003-2007 e 15,4\% em 2007-2012). Note-se que a principal diferença entre os dois períodos é a inversão da ordem das respostas "definição de diretrizes para a saúde" (mencionada primeiro em 2003-2007) e "controle social" (mencionada primeiro em 2007-2012).
} 
respostas continua muito alto (41\%). A prevalência da resposta "pactuação/articulação/democratização" é igualmente observável nos dois períodos estudados (69,2\% em 2003-2007 e 46,2\% em 2007-2012), bem como a alta incidência de "não sabe/não respondeu" (30,8\% em 2003-2007 e 46,2\% em 2007-2012). Cabe notar que a resposta de "suporte técnico para decisões" aparece somente em 2007-2012, com 7,7\%.

Tendo em vista este quadro, ganham importância os mecanismos institucionais de fiscalização. Uma das importantes instituições da democracia brasileira, o Ministério Público (estaduais e federal) tem, cada vez mais, avançado no campo da defesa do direito à saúde, seja judicial ou extrajudicialmente. Com o objetivo de averiguar se o cenário nacional se repete no Estado do Rio de Janeiro, foi perguntado aos gestores se o Ministério Público do Estado do Rio de Janeiro tem atuação na SES-RJ.

As respostas iniciais parecem confirmar esta perspectiva, uma vez que 87,2\% dos entrevistados responderam que existe tal atuação. No entanto, no momento de especificar que tipos de ações eram tomadas, a atuação judicial, ou seja, com ingresso de uma ação no Poder Judiciário, ainda aparece como preponderante $(35,9 \%)$ sobre o papel fiscalizatório extrajudicial do Ministério Público ("fiscalização e apuração de irregularidades" aparece com 17,9\% e firmamento de Termos de Ajustamento de Conduta, com 5,1\%). Apesar disso, a maioria dos gestores considera que houve alteração no processo decisório da SES-RJ em resposta às ações do MPE.

Ainda sob a perspectiva do controle e fiscalização, o Conselho Estadual de Saúde é uma das mais importantes instituições de auxílio da gestão. Passaremos agora à análise de seu papel do Estado do Rio de Janeiro.

\section{Parte 3 - Controle Social da Gestão Estadual de Saúde}

\subsection{Conselho Estadual de Saúde: perfil e participação social}

Respondendo à mobilização da sociedade civil, a Constituição Federal de 1988 descentralizou a gestão das políticas públicas e sancionou a participação da sociedade civil nos processos de tomada de decisão. A regulamentação das normas constitucionais propiciou inovações institucionais: conferências municipais, estaduais e nacionais temáticas e conselhos gestores de políticas públicas de caráter permanente correspondentes. Os novos arranjos institucionais buscavam ampliar a influência de diversos atores sociais no processo de 
formulação e implementação da política de saúde. Como vimos, contudo, o desenvolvimento institucional do SUS acabou por afastar o desenvolvimento das políticas do controle social.

É claro, no entanto, que a institucionalização dos conselhos de políticas públicas, a partir da Constituição de 1988, e dos Conselhos de Saúde, através da Lei 8142/90, demonstrou historicamente um avanço no enraizamento da democracia participativa. A institucionalização de procedimentos participativos em organismos perenes enfatizou uma inovação democrática, caracterizada principalmente pela alteração das relações entre Estado e sociedade. A um só tempo, houve aumento substancial de atores de diferentes estratos das demandas societárias que foram integrados ao processo deliberativo (associativismos, sindicatos, conselhos profissionais, ONGs) e o incentivo de aumentar o nível de democraticidade nas arenas decisórias de governos (federal, estaduais e municipais).

Fica a questão: se, por um lado, no caso dos Conselhos de Saúde, pode-se afirmar uma inegável onda de institucionalização da participação; por outro, ainda permanece como dilema e desafio a legitimidade do papel dos conselheiros de saúde, ou seja, como a gestão e os próprios conselheiros encaram a questão do afastamento do SUS do controle social.

Nesta parte do artigo procuraremos entender como o Conselho Estadual de Saúde do Rio de Janeiro (CES-RJ) desenvolve suas atividades nesse contexto. Em primeiro lugar, traçaremos um perfil dos participantes do Conselho. Em segundo lugar, procuraremos analisar alguns dilemas concernentes à dinâmica da participação social do SUS, teremos como objetivo principal analisar as relações entre conselheiros representantes da sociedade e dos profissionais de saúde e os atores estatais (gestores da Secretaria Estadual de Saúde do Rio de Janeiro - SES/RJ), durante as gestões dos governos Rosinha Garotinho (2003-2006) e Sérgio Cabral (2007-2012).

Os dados aqui apresentados são fruto da pesquisa "Políticas de Saúde, Gestão, Intersetorialidade, Regionalização e Participação Social no Estado do Rio de Janeiro”. Foram entrevistados 19 conselheiros, participantes das duas gestões acima referidas. Cabe aqui uma nota metodológica: em razão de dificuldades burocráticas encontradas ao longo da realização desta pesquisa, a maior parte dos entrevistados pertence ao período 2007-2012. Como veremos, no entanto, este fato acaba por não influenciar na apresentação dos dados. De fato, um número considerável de conselheiros presentes na gestão atual já vinha do período anterior. Em razão desta pouca rotatividade no Conselho considerou-se como aceitável apresentar os dados aqui reunidos como também passíveis de cotejo com os dados sobre a 
gestão do período 2003-2007. De fato, 63,2\% dos entrevistados já participavam da gestão anterior e, em média, os entrevistados começaram a fazer parte do Conselho em 2006.

No que tange à sua participação interna no CES-RJ, 84,2\% dos entrevistados afirmaram fazer parte de alguma comissão interna do CES. A Comissão que aparece no maior número de questionários é a Comissão Executiva (com 31,3\% de questionários válidos), seguida pela Comissão de Qualidade e Gestão e pela Comissão de Vigilância em Saúde (25\% em ambas), pela Comissão de Legislação $(18,8 \%)$ e pela Comissão de Orçamento e Finanças $(12,5 \%)$.

Os dados sobre participação em comissões internas são interessantes porque demonstram interesse dos conselheiros em participar da gestão. Com efeito, quando perguntados sobre qual é o papel de cada uma das comissões internas do CES, os entrevistados responderam que a função mais importante destas comissões é "encaminhar demandas da sociedade" (com 73,7\% de "muito importante"), seguida por "discussão de questões específicas" (com 68,4\%), "deliberar sobre questões específicas” (57,9\%) e "acelerar processos" e "propor pautas" (ambas com 41,1\%).

A maioria dos conselheiros parece ser bem experiente. Além do alto percentual que já ocupava cadeira no período anterior, $52,6 \%$ dos entrevistados disseram terem ocupado assento em outro conselho de políticas públicas. Destes, aparecem em $70 \%$ dos questionários válidos os "conselhos municipais de outras políticas"; seguidos pelos "conselhos municipais de saúde" (50\%); pelos "conselhos estaduais de outras políticas" (30\%); "conselho nacional de saúde" (10\%) e "conselhos distritais de saúde" (10\%).

Esta experiência não parece ser suficiente, todavia, para garantir a efetiva atuação do Conselho. De acordo com as respostas dos questionários, 68,4\% dos entrevistados responderam que o CES não cumpre com todas as disposições previstas pelo Regulamento Interno. Os motivos apresentados foram, em ordem decrescente: "indução da gestão" (30,8\%), “o CES não atua pelo Estado do Rio de Janeiro” (23,1\%), “o CES não cumpre com seu papel fiscalizador" $(10,5 \%)$ e "desconhecimento" $(7,7 \%)$.

\subsection{Conflitos e relações com a Secretaria Estadual de Saúde}

A importância do Conselho Estadual de Saúde do Rio de Janeiro na formulação e implementação de serviços de saúde é colocada em cheque a partir das primeiras avaliações dos gestores sobre o papel do Conselho. Apesar de, numa análise geral, vermos que a maioria 
dos gestores considera a atuação do CES "satisfatória" com 44,4\%, a seguir temos "medianamente satisfatória" com 38,9\%, insatisfatório com $13,9 \%$ e, por último, "amplamente satisfatório" com 2,8\%. ${ }^{5}$ Quando perguntados sobre como o CES contribui para a gestão estadual, 45,7\% dos gestores responderam "com a aprovação de propostas de planejamento", 28,6\% consideraram que o CES "tem um papel pouco definido/influencia pouco" e 5,7\% responderam que, na verdade, "ele tem papel desagregador/atrapalha". Ou seja, a maioria absoluta dos gestores considera que o papel do Conselho se resume a aprovar questões estabelecidas previamente pela gestão ou que ele não tem um papel definido. Apenas $20 \%$ responderam que o CES contribui através de "controle e fiscalização".

A visão de que a relação entre o Conselho e a Secretaria é boa se replica nas respostas dos conselheiros. A atuação da representação da Secretaria Estadual de Saúde no Conselho Estadual de Saúde foi classificada em "muito boa" com 15,8\% das respostas dos entrevistados, "boa" com 47,4\%, "regular" com 5,3\% das respostas, "ruim" com 15,8\%, "muito ruim" com 10,5\% e "não sabe/não respondeu" com 5,3\% das respostas. Na verdade, $57,9 \%$ dos conselheiros entrevistados consideram que os gestores da SES ouvem, respeitam e acatam as deliberações do CES (36,8\% consideram que não e 5,3\% não sabem ou não responderam). Dentre os que responderam que consideram que a SES ouve as decisões do CES, $41 \%$ consideram que a SES realmente ouve e acata as deliberações do CES, $25 \%$ consideram que a SES ouve, mas nem sempre acata, e 16,6\% responderam que a SES somente respeita as propostas que o CES faz, e não suas críticas.

No entanto, a resposta dos gestores sobre a pouca contribuição do CES em termos de controle contrasta dramaticamente com a visão dos conselheiros sobre o seu papel. Sobre qual papel deveria ser desempenhado pelo CES frente a SES, os entrevistados responderam, em ordem decrescente: 1) fiscalização $(77,8 \%), 2)$ deliberação das políticas propostas pela SES $(42,1 \%)$, e 3$)$ papel crítico em relação as ações da SES $(36,8 \%)$.

\footnotetext{
${ }^{5}$ Vemos que essa tendência para a opção satisfatório é bastante influenciada pelo período 2003-2007, uma vez que no período 2007-2012 vemos que a maior parte dos gestores considera a atuação do Conselho Estadual de Saúde "medianamente satisfatória" com $50 \%$. A seguir vemos as opções satisfatório com $33,3 \%$ e insatisfatório com apenas $16,7 \%$. Já no que tange ao período $2003-2007$, vemos que a maioria absoluta dos gestores classificou a atuação do CES como "satisfatória" com $66,7 \%$, a seguir temos "medianamente satisfatório" com $16,7 \%$ e depois "insatisfatório" e "amplamente satisfatório", ambos com 8,3\%.
} 
Este tipo de dualidade na interpretação sobre o comportamento do CES - de um lado uma relação cordial, de outro falta de influência no processo decisório - permanece sempre presente nas respostas dos gestores. Neste sentido, $81,6 \%$ dos gestores consideram que o CES contribui com a gestão da SES. Quando perguntados sobre a forma de contribuição, $25 \%$ dos gestores respondeu "partilhando decisões", 25\% "participando de reuniões, fóruns e conferências", 15,6\% "aprovando as deliberações da SES" e 15,6\% "fiscalizando a gestão". 15,5\% não sabem ou não responderam. Apesar destas respostas, 61,8\% dos gestores responderam que o CES não exerce controle social enquanto representante da sociedade. Os percentuais não se alteram quando comparamos as duas gestões.

Chamados a especificar o motivo pelo qual o CES não exerce controle social enquanto representante da sociedade, vemos que em $66,7 \%$ das entrevistas válidas apontam que "as representações são limitadas por interesses corporativos", em $61,9 \%$ dos questionários válidos o motivo apontado é que "é pouco qualificado para exercer a função", em 47,6\% dos questionários aparece a resposta "é demasiado partidarizado", em 23,8\% dos questionários válidos aparece a resposta "faltam representantes de vários setores da sociedade", empatados na quinta posição temos "não há consenso sobre o que seja controle social" e "é mais obstáculo do que ajuda”, aparecendo em 14,3\% dos questionários válidos, e, por último, aparecendo em 9,5\% dos questionários válidos, "o formato do conselho não contribui para o processo decisório da SES".

Esta visão sobre a pouca capacitação dos conselheiros para assumir sua posição se repete quando analisamos as respostas dos próprios conselheiros. De acordo com as respostas dos questionários, $68,4 \%$ dos entrevistados consideram que os conselheiros representantes da sociedade não estão suficientemente capacitados para tomar decisões. Os motivos apresentados para esta falta de capacitação foram "falta de capacitação/educação permanente" com 61,5\%; "falta independência política para decidir" com 38,5\%; "falta conhecimento sobre o papel do conselheiro" com 46,2\% do total de entrevistados.

Tudo isso demonstra que o CES-RJ não tem papel na formulação da política de saúde. Com efeito, o Conselho se apresenta como uma instância burocrática de aprovação da política e não como um espaço de participação social. Isso se torna claro quando vemos que os próprios conselheiros não consideravam a participação na formulação de políticas como relevante papel do Conselho. Desta forma, o CES-RJ aparece como um conselho distanciado da sociedade e incapaz de transcender a sua própria existência enquanto instância da gestão. 
Ou seja, o Conselho se transformou em mais uma instância do estado, cujo principal papel é a aprovação de políticas das quais não participa da elaboração.

\section{Conclusão}

O artigo que apresentamos teve por objetivo analisar a política estadual de saúde no que se refere aos processos de formulação, implementação e participação, no Estado do Rio de Janeiro (RJ), no espaço compreendido entre 2003 e 2012. Concentramo-nos sobre o papel da Secretaria Estadual de Saúde do Rio de Janeiro (SES-RJ) e do Conselho Estadual de Saúde (CES-RJ) na formulação e implementação de políticas públicas e no relacionamento entre estas instâncias. Procuramos analisar estes pontos a partir dos antecedentes institucionais do SUS e das articulações históricas e políticas típicas deste estado.

Assim, o desenvolvimento do SUS a partir do movimento da Reforma Sanitária é marcado por uma tensão estruturante entre instituinte e instituído. De fato, se a Constituição de 1988 buscou um modelo de saúde próximo daquele das social-democracias europeias, sua construção se deu em um contexto no qual a disputa ideológica favoreceu amplamente o projeto neoliberal, reorganizando as relações entre Estado e sociedade em bases distintas daquelas pressupostas pelos formuladores da Reforma. A conjuntura adversa aos projetos de corte universalista dos anos 1990 contribuiu para retrocessos importantes na construção da saúde como um valor público e direito coletivo e para a fragmentação das bases de apoio político da Reforma Sanitária e a ascensão de novos atores políticos, principalmente advindos do próprio corpo burocrático estatal, que assumiram a primazia sobre a institucionalização do SUS.

Por outro lado, a cronologia de implementação do SUS também influencia a conformação atual de poder político. Neste sentido, descentralização municipalizante e regionalização correspondem a momentos definidos na cronologia de implementação do SUS. A descentralização político-administrativa foi concebida compreendendo a "ênfase na descentralização dos serviços para os municípios", associada à "regionalização e hierarquização da rede de serviços de saúde" (art. $7^{\circ}$, Lei 8.080/90). Contudo, seguindo o movimento que marcou a descentralização das políticas sociais no Brasil na década de 1990, a opção política do primeiro decênio de implantação do SUS foi priorizar a municipalização da saúde. 
A opção pela municipalização, realizada através do contato direto entre a União e os municípios através de uma normatização intensa por parte do Ministério da Saúde, fez com que, por um lado, houvesse um acúmulo de poder no Poder Executivo federal e, por outro, acabou por retirar dos estados sua função na formulação da política de saúde. No entanto, a extrema fragmentação dos serviços que foi consequência da municipalização fez com que a regionalização entrasse com força na agenda nacional.

Todo esse movimento pela regionalização acaba por fortalecer ainda mais os atores políticos institucionais, como os secretários de Saúde estaduais e municipais, que passaram a contar com diversas instâncias de pactuação. As diversas tentativas de inclusão dos estados no processo decisório e na administração do SUS foram realizadas priorizando a participação de gestores e da própria burocracia estatal dos estados e municípios. A desigualdade na distribuição de recursos políticos e poder entre os atores é agravada e, com isso, tende a favorecer cada vez mais grupos de gestores e grupos corporativos, impedindo que os ideais da reforma se concretizem e garantam a centralidade do cidadão no processo decisório.

Todo o movimento da Reforma Sanitária só foi possível porque a Constituição de 1988 é um marco jurídico singular na história do Estado brasileiro porque se trata da primeira Constituição Nacional que define a existência inalienável de direitos sociais universais e que reside necessariamente em uma nova forma de convivência e de relação entre sociedade e Estado. Numa sociedade como a brasileira, o Estado tem ainda mais a obrigação de prover, a toda e qualquer pessoa nascida no país, de um novo conjunto de direitos que possibilitariam uma vida com saúde, educação, moradia, direitos relacionados à maternidade, aposentadoria e desemprego. Em suma um caminho para uma sociedade mais justa e menos desigual. Nestes termos, o Estado (Executivo, Legislativo e Judiciário) e as suas instituições são coparticipes através do exercício das suas funções, da efetivação do bem estar da sociedade. Especialmente a obrigatoriedade de proporcionar uma vida saudável e plena para todos.

Um ano mais tarde, no âmbito desses princípios os direitos de cidadania social se espelharam na Constituinte Estadual e na elaboração da Constituição do Estado do Rio de Janeiro. A aprovação da Constituição Estadual, que foi bastante tumultuada pela disputa de diversas bancadas e interesses em jogo, foi aprovada pela maioria dos deputados eleitos em 1986, imediatamente após a transição à democracia e acompanhou a Constituição Nacional. A Assembleia Legislativa ficou presidida durante 10 anos pelos deputados Sergio Cabral e Jose Nader que procuraram firmar o Legislativo na opinião pública como um órgão de governo 
voltado para o interesse popular e para o desenvolvimento político e econômico do Estado do Rio de Janeiro.

Apesar desse movimento pela construção da saúde como um direito social, a máquina política é um traço forte da política estadual, não apenas no que se refere à política de saúde, mas à forma sob a qual se desenvolvem e agem instituições governamentais, partidos e os próprios líderes de governo, sejam estes líderes partidários, sejam eles burocracia do estado. O exercício da política é extremamente personalizado e existe pouco nos partidos a crença a respeito de movimentos e de processos históricos sob os quais sejam baseadas as decisões e escolhas realizadas no longo prazo. A não existência da cidadania para além da sua definição formal é a percepção que, em geral, a sociedade recebe das suas instituições de governo, do Legislativo e do Judiciário. Só contam as influências políticas, uma boa posição econômica e, em última instância, a educação.

Por esse motivo sempre há um grau de impunidade no governante que intimida a sociedade. Ou seja, o longo prazo da vida societária não é questão prioritária de governo, apenas as conjunturas são determinantes e nestas há que se fazer boas negociações e obter saldos decisivos para a presente rodada. Esta forma de agir em política somente pode se reproduzir se houver uma máquina política capaz de sustentar comportamentos políticos baseados na ação personalista dos atores políticos.

Todo este panorama - alijamento dos entes federativos estaduais do papel principal na formulação da política de saúde, seguida pela tentativa de retomada de um papel através da preponderância da atuação de agentes estatais e afastamento da participação social; existência de uma Constituição Federal e uma Constituição Estadual que buscam construir o saúde como um direito social; a existência de uma máquina política no estado que privilegia arranjos com vantagens imediatas ao invés de implementação de uma política de longo prazo - devem ser considerados como razões para a atual situação da SES e do CES.

Neste sentido, vemos que a forma em que acontece o processo decisório não envolve procedimentos recorrentes e previstos previamente à escolha de quem vai e quem não vai participar e também não envolve um conjunto permanente de subsecretários e assessores, inclusive parte destes entende que isto depende do tipo de decisão e que deixar registros de como se tomam as decisões e dos resultados das mesmas parece não ser uma preocupação do Executivo estadual da saúde. A não existência de registros se relaciona com a transparência da gestão, mas não apenas, se levarmos em consideração que em toda instituição existem 
diferenças entre as preferências políticas dos atores, o procedimento observado poderia se relacionar com o resguardo de conflitos político-ideológicos intrainstitucionais.

O processo de retomada da importância do estado como parte do processo de política de Saúde também aparece muito claramente quando analisamos o Rio de Janeiro. Como demonstram os diversos dados sobre a relação do Estado do Rio de Janeiro com o governo federal ou com seus municípios, vemos a retomada da importância do estado. No entanto, acreditamos que as relações federativas não enveredam pela construção de um Pacto Federativo que envolva os estados, municípios e União na Federação. Trata-se de acordos que se regem por "afinidades eletivas" político-partidárias e, por sua vez, os partidos pelas suas hierarquias políticas e, principalmente, pelas que exercem o poder. Isso fica claro quando analisamos os dados sobre o pouco conhecimento dos gestores sobre a função do estado nas instâncias interfederativas do SUS.

Quanto à participação social, acompanhando a tendência de alijamento da tomada de decisões do controle social, vemos o CES-RJ não tem papel na formulação da política de Saúde. Com efeito, o Conselho se apresenta como uma instância burocrática de aprovação da política e não como um espaço de participação social. Isso se torna claro quando vemos que os próprios conselheiros não consideravam a participação na formulação de políticas como relevante papel do Conselho. Desta forma, o CES-RJ aparece como um conselho distanciado da sociedade e incapaz de transcender a sua própria existência enquanto instância da gestão. Ou seja, o Conselho se transformou em mais uma instância do estado, cujo principal papel é a aprovação de políticas das quais não participa da elaboração.

\section{Referências Bibliográficas}

ARRETCHE, M. "Mitos da descentralização: mais democracia e eficiência nas políticas públicas?" Rev bras ciên soc. 1996; 11:44-6

"Federalismo e relações intergovernamentais no Brasil: a reforma de programas sociais." Dados. 2002; 45 (3). 1962

BACCHACH, P.; BRARATZ, M.S. , Two faces of Power. American Political Science Review, 56, 1962.

DINIZ, E. Voto e Maquina Política: patronageme clientelismo no Rio de Janeiro, São Paulo: Paz e Terra, 1982.

DOURADO, Daniel de Araujo; ELIAS, Paulo Eduardo Mangeon. Regionalização e dinâmica política do federalismo sanitário brasileiro. Rev. Saúde Pública, São Paulo , v. 45, n. 1, Feb. 
$<$ http://www.scielo.br/scielo.php?script=sci_arttext\&pid=S0034-

89102011000100023\&lng=en\&nrm=iso >. access on 25 Sept. 2013. http://dx.doi.org/10.1590/S0034-89102011000100023.

FLEURY, S. “A análise necessária da reforma sanitária.” Saúde Debate, n. 22, p. 25, 1988. "Reforma sanitária brasileira: dilemas entre o instituinte e o instituído." Ciênc. saúde coletiva. 2009, vol.14, n.3

GERSCHMAN, S., Municipalização e inovação gerencial : Um balanço da década de 1990. Revista Ciência \& Saúde Coletiva, 6(2): 417-434,2001.

LUKES, S. Power: a radical view. London:Macmillan, 1974.

Offe, K. Problemas estruturais do Estado capitalista. Rio de Janeiro: Tempo brasileiro, 1984.

PAIM, J S. Reforma Sanitária Brasileira: Contribuição para a compreensão crítica. Rio de Janeiro: Editora Fiocruz, 2008.

Poulantzas, N. O Estado, o poder e o socialismo. Rio de Janeiro: Graal Editora, 1980. Parte II,

RAKOVE, M.L..Don't Make no Waves, Don't backno Loser :an insider's analysisof the daley machine, Bloomington: Indiana University Press, 1975

VIANA, A. L. d' Á. ; Viana, Ana Luiza d\&amp ; LIMA, Luciana Dias de ; OLIVEIRA, Roberta Gondim de . Descentralização e federalismo: a política de saúde em novo contexto - lições do caso brasileiro. Ciência \& Saúde Coletiva, Rio de Janeiro, v. 7, n. 3, p. 493-507, 2002. 